\title{
A synopsis of surgical training in Sri Lanka: the past
}

\author{
Pramodh Chandrasinghe \\ Department of Surgery, Faculty of Medicine, University of Kelaniya, Sri Lanka
}

\begin{abstract}
First of a three part series based on personal correspondence with Professors Arjuna Aluwihare, A.H. Sherriffdeen and Channa Rathnathunga on their experience and memories of surgical training in Sri Lanka.
\end{abstract}

The documented history of surgical training dates back to over two millennia where Sushruta describes the ancient equivalence of modern skill workshops in 'Sushruta Samhita' [1]. Surgery is an arm of medicine that requires dexterity coupled with an unconditional surrender to patient well-being as those who 'go under the knife' have the utmost faith in the surgeon. Surgical training in modern medicine dates back to medieval times where training and licensing were required to perform surgery in London during the late 14th century. Training in surgery has largely been an apprenticeship, which has evolved with time into a structured curriculum-based programme. This article aims to describe the evolution of surgical training in Sri Lanka during the past six decades based on personal communication with three senior surgeons in the country. The information is based on their personal experience as surgical trainees and administrators in postgraduate training.

From the early 19th century, surgeons were deployed to Sri Lanka from the United Kingdom [UK]. Following the era of British Surgeons, by the early 20th century Sri Lankan-born surgeons in the likes of S.C Paul, A.M. De Silva and R.L Spittle took over the craft of surgery. There is not much published literature on the evolution of modern surgical training in Sri Lanka. However, it was mostly based on the British system largely influenced by the colonial ruling. In the early days, the entire training took place in the UK at renowned hospitals such as The Kings College, St. Thomas's and The Royal London hospital, following which they completed the fellowship exam of the Royal College of Surgeons [FRCS]. M.A De Silva was the first Ceylonese surgeon to obtain the title of FRCS [2]. By the mid 20th century, the pathway to becoming a surgeon changed to completing the 1st part of the FRCS in Sri Lanka coupled with

Correspondence: Pramodh Chandrasinghe

E-mail: pramodh@kln.ac.lk

(iD) https://orcid.org/0000-0002-3485-961X

Received: 21-11-2021 Accepted: 21-11-2021

DOI: http://doi.org/10.4038/sljs.v39i3.8917 a short training in the UK and completion of the fellowship. Prof. Aluwihare recalls his early days with the famous surgeon, Dr. Bartholamews during the early 1960s. Performing a tracheostomy on a sick child as an intern medical officer had further reinforced his liking towards surgery. Pursuing his ambitions, he was able to sit for the first part of the FRCS in Sri Lanka. The second part had to be completed in the UK following which he chose to pursue an academic pathway at Cambridge and London before returning to Peradeniya in 1971. According to Prof. A.H Sheriffdeen, like most newly qualified doctors in Colombo, he chose to work at the Mental Institute in Angoda as it provided ample time to study for his FRCS primary exam. At that time [the late 1960s] following the primary exam a young surgeon had to go through 18 months of general surgery and 6 months of orthopaedics/ trauma before flying off to the UK for the FRCS final exam. The teaching hospitals in Colombo and Kandy have been the only approved centres by the RCS for this local training until the late 1970s. Following the completion of the fellowship, they were posted for 6 months in a NHS post after which they returned to Sri Lanka. According to professor Channa Rathnathunga, the healthy relationship between the British and Sri Lankan surgeons helped the trainees to get placements at RCS accredited units in the UK. The gala that followed the completion of the part I exam in Colombo and later in Kandy was the 'landmark event' that strengthened this relationship according to Prof. Rathnathunga. Sri Lanka being a popular destination for English examiners for obvious reasons helped this tradition to perpetuate for years to come. From 1971 onwards the RCS has made it compulsory to spend one year at a NHS trust hospital before sitting for the final fellowship exam, a rule that applied only for trainees from the subcontinent.

Upon return, most surgeons had to function as a resident surgeon under a senior colleague till a post was vacant. This time period, according to Prof. Sheriffdeen, provided space for reflective learning while functioning as a surgeon. The cost of the primary FRCS exam in the early days was borne by the government, alleviating the burden on trainees. However, the cost of travelling to the UK had to be borne by the trainees. The economic policies in the late 1960s till late 70 s had allowed only $£ 3$ to be released as foreign currency. Professor 


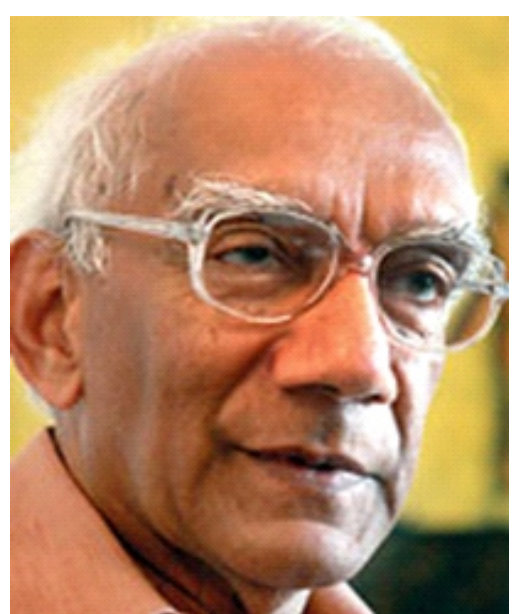

Prof. Arjuna Aluwihare,

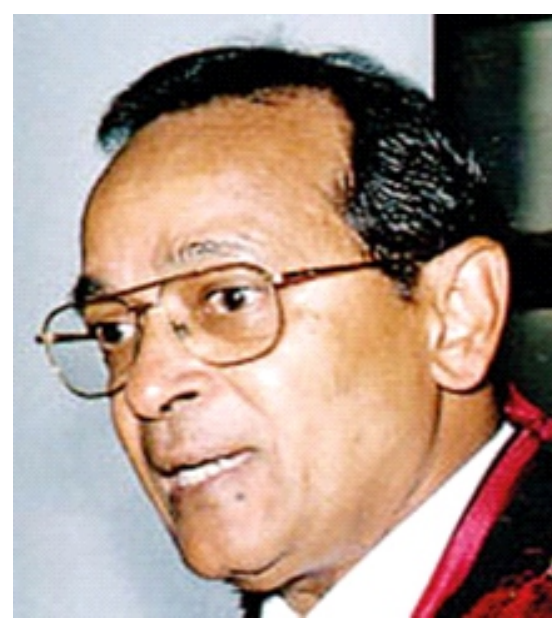

Prof. A.H.Sheriffdeen,

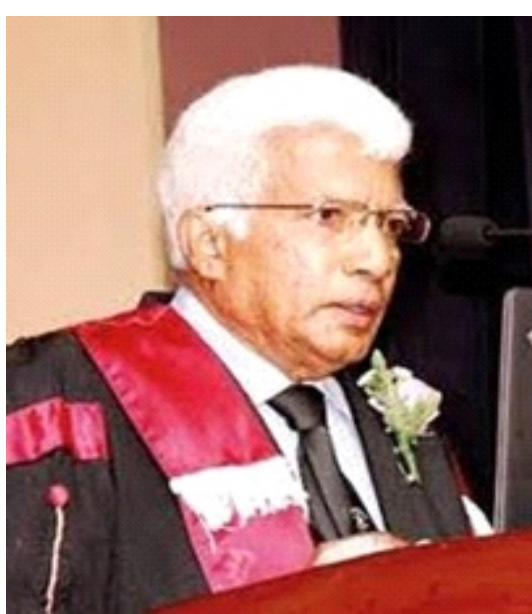

Prof. Channa Rathnathunga

Three of the senior surgeons who have gone through surgical training in Sri Lanka during 1960s and 70s. They have all served as chairpersons of the board of study for surgery at the PGIM

Rathnathunga feels that these difficulties prompted some of the talented trainees to stay back in the UK after completing their training.

There had been no formal teaching programme for surgical trainees apart from several lectures by eminent surgeons at that time. Most of the training has been 'learning on the job' type. Training course at the RCS and some of the leading hospitals in London were available for those who could afford them. According to Prof. Rathnathunga, Sri Lankan trainees were solid in their surgical principles and basic skills compared to the English counterparts owing to the high volume of patients they experienced during the mandatory 2 years of local training. However the year spent in the UK helped them to be more conversant with the advanced technology, which has helped at the FRCS exit examination.

As S. Sivaganesh states in his editorial to the Sri Lanka Journal of Surgery, 1980 was indeed marked a 'watershed' in postgraduate medical education in Sri Lanka with the establishment of the Postgraduate Institute of Medicine [PGIM] [3]. However, the initial attempt at forming a local authority for postgraduate training in the mid 1970s has failed. Prof. Sheriffdeen refers to this as the 1st Phase of the PGIM, which was then called the Institute of Postgraduate Medicine [IPM]. The Government Medical Officer Association [GMOA] had been one of the strongest opponents to a local system. The 'Phase II' of the PGIM, which took effect in 1980, has been a success and locally accredited postgraduate qualification under a board of study [BOS] for surgery was established.

Apart from general surgery, the main specialties of orthopaedics, cardio-thoracic, plastic and genitourinary surgery were established practices by the 1960s. There were no separate training programmes for sub specialties and the qualified surgeons took up the disciplines based on requirement of services or influence of their trainers. With time the subspecialties were established based on individual preferences and the lobbying capabilities of the said individuals. At a time when the Ministry of Health did not possess projections for the requirements of specialists, selffunded training and equipment acquired through grants have paved the path to establishment of sub- specialties preceded by the development of the practice at the respective institutions.

With the establishment of the PGIM, the BOS in Surgery became the sole authority of accrediting surgical practice in Sri Lanka. However lateral entry for FRCS qualified trainees was allowed following completion of the MS part II exam. With the sub-specialties gradually branching out, the BOS in surgery eventually had to accommodate subspecialty boards affiliated to it. Surgical training during the post PGIM era will be discussed in the second part of the series.

All authors disclose no conflict of interest. The study was conducted in accordance with the ethical standards of the relevant institutional or national ethics committee and the Helsinki Declaration of 1975, as revised in 2000 .

\section{References}

1. Singh V. [2017]. Sushruta: The father of surgery. National journal of maxillofacial surgery, 8[1], 1-3. https://doi.org/10.4103/njms.NJMS_33_17

2. https://livesonline.rcseng.ac.uk/client/en_GB/lives/search/resut $\mathrm{s}$ ?qu $=\% 22 \mathrm{RCS}$ :

E004998\%22\&rt=false||IDENTIFIER||Resource+Identifier ; accessed 14th September 2021

3. Sivaganesh S. Surgical training in Sri Lanka - where next?. Sri Lanka Journal of Surgery. 2014;31[3]:1-2. 